\title{
Immunofluorescence Examination of Typical Staphylococcus aureus Variants and L-forms for Clumping Factor
}

\author{
By K. L. ELKINS, R. M. HYDE AND FLORENE C. KELLY \\ Department of Microbiology, University of Oklahoma Medical Center, \\ Oklahoma City, Oklahoma 73104, U.S.A.
}

\section{(Accepted for publication 24 September 1969)}

\begin{abstract}
SUMMARY
Encapsulated coagulase-positive staphylococci which do not clump with fibrinogen possess the clumping factor antigen as well as other cell-wall antigens characteristic of Staphylococcus aureus. Variants which were negative for both coagulase and clumping factor not only lacked the clumping factor antigen but also other $S$. aureus surface antigens. L-forms did not remove clumping inhibiting antibody from $S$. aureus antisera. Antisera which were relatively high in clumping-inhibiting antibodies, but low in agglutinins, gave no fluorescence with coagulase-negative, clumping factor-negative variants or L-forms. The clumping factor, probably a cell-wall component of $S$. aureus, is absent in the penicillin-induced, stable L-form.
\end{abstract}

\section{INTRODUCTION}

The characteristic clumping of coagulase-positive staphylococci in the presence of fibrinogen is attributed to a factor (bound coagulase or clumping factor) which is presumed to be a surface component of the cocci. Duthie (1954) reported that an antigen of Staphylococcus aureus, which was released into the culture medium upon autolysis, induced production of antibodies which inhibited the clumping reaction. This antigen has not been detected in staphylococcal extracts which precipitate fibrinogen (Rotter \& Kelly, I966; Blackstock, Hyde \& Kelly, 1968). Kato \& Omori (1959) verified the observation of Duthie (I954) that trypsinized $S$. aureus cocci lose the ability to clump in fibrinogen solution, and they no longer absorb the clumpinginhibiting antibodies from antiserum. It was assumed that the release of clumping factor into the medium of ageing cultures, as well as its loss upon refrigeration and trypsinization, is probably due to a 'peeling off' of cell-surface substance. Gorrill, Klyhn \& McNeil (1966) found that clumping factor was either destroyed or removed by sonic vibrations. A remnant of cell-wall material may be present on some or all of the so-called L-forms of $S$. aureus (Pratt, I966; Hamburger \& Carleton, 1966); clumping factor could be a component of this cell-wall remnant. Coagulase and clumping factor are closely associated in the bacterial form of typical $S$. aureus strains, and L-forms of these strains are known to produce coagulase (Mattman, Turnstall \& Rossmoore, I96I).

In this immunofluorescence study typical coagulase-positive cocci, clumping factornegative and L-forms of Staphylococcus aureus were tested with antisera of known agglutinating and clumping-inhibiting antibody content. 


\section{METHODS}

Staphylococcal strains. Six typical Staphylococcus aureus strains were used: 2095, 3I89 and 2253, strains of known serological type (Cohen \& Smith, 1964) supplied by Dr J. O. Cohen; J I7, serologically of Cowan's group I (from Dr K. Jensen, who used it in his antigen A studies: personal communication); 604, a wild strain isolated here; the SMITH strain (from Dr G. A. Hunt). Also used were: the coagulase-negative, clumping factor-negative variants of strains $\mathrm{J} I 7$ and 604 designated $\mathrm{J} I 7 \mathrm{M}$ and $604 \mathrm{M}$, respectively; strain Sv, an encapsulated, mouse-virulent variant of the SMITH strain (Hunt \& Moses, 1958); and $\mathrm{K} 6$, an encapsulated, mouse-virulent strain which was isolated here from the nasopharynx of a healthy carrier in 1956. Although coagulasepositive, neither strain SV nor strain $\mathrm{K} 6$ clump in fibrinogen solutions.

Induction and cultivation of L-forms. Five coagulase-positive, clumping factorpositive strains $\left(2095,2253,3189,604\right.$ and $\mathrm{II}_{7}$ ) were induced to L-form growth. The inducing medium was similar to that used by Marston (196r $a$ ) and Williams (1963). A concentrated inoculum was prepared by centrifuging a 5 to $8 \mathrm{hr}$ Brain-HeartInfusion (Difco) broth culture $\left(37^{\circ}\right)$ and resuspending the cocci in one-fifth the original volume of broth. One-half millilitre $(0.5 \mathrm{ml}$.) was plated on Brain-Heart-Infusion (Difco) medium which contained I \% (w/v) Special Agar-Noble (Difco), $5 \%(\mathrm{w} / \mathrm{v})$ sodium chloride, $10 \%(\mathrm{v} / \mathrm{v})$ horse serum and 1500 units penicillin $\mathrm{G} / \mathrm{ml}$. L-colonies, which developed after $\left(37^{\circ}\right)$ incubation, were subcultured first on the inducing agar medium and thereafter in a similar liquid medium. Once stable L-form growth was obtained, subsequent broth cultures were shaken at low speed on a Burrell wrist action shaker during a $48 \mathrm{hr}$ incubation period at $37^{\circ}$. L-forms were also grown in soft agar medium prepared by adding $0.15 \%(\mathrm{w} / \mathrm{v})$ Special Agar-Noble (Difco) to the liquid medium. Modifications of the soft agar medium included addition of $4 \%(w / v)$ human fibrinogen (Merck, Sharp \& Dohme, West Point, Pa.) or bovine fibrinogen (Armour Fraction I, Armour Pharmaceutical Co., Kankakee, Ill.) for testing clumping factor activity, and incorporation of I \% (v/v) rabbit plasma in the fibrinogen-soft agar for demonstrating free coagulase (Alami \& Kelly, 1959).

Preparation and use of antisera. Immunization of rabbits with typical Staphylococcus aureus strains began with two $0.5 \mathrm{ml}$. intravenous injections of formalinized $\left(2 \times 10^{9}\right.$ cocci $/ \mathrm{ml}$.) vaccine in the first week, and was continued, for a total of 8 weeks, with similar, biweekly injections of cocci which had been heated at $65^{\circ}$ for $2 \mathrm{hr}$. Less than I $\%$ of the heated cocci were viable.

Samples of each antiserum were absorbed with clumping factor-negative Staphylococcus aureus variants and with L-forms. L-forms separated from a $300 \mathrm{ml}$. broth culture were washed once in $3 \%(\mathrm{w} / \mathrm{v}) \mathrm{NaCl}$ solution and antiserum was added to the sedimented growth. Absorption, with washed typical cocci or L-forms, was allowed to proceed at $37^{\circ}$ for $2 \mathrm{hr}$ and at $4^{\circ}$ for an additional $24 \mathrm{hr}$. Antisera against three strains were absorbed with lyophilized supernatant fluid of the broth culture in which the L-form had grown, as well as with lyophilized, uninoculated, L-form broth medium. Antisera were held at $-2 \mathrm{I}^{\circ}$ until used in agglutination, clumping inhibition and indirect fluorescent-antibody tests. In immunodiffusion experiments antiserum was substituted for horse serum in L-form agar medium.

Indirect fluorescent-antibody tests. Fluorescein isothiocyanate-labelled sheep antirabbit gamma globulin (Colorado Serum Company, Denver, Colorado) was applied 
to cocc1 and L-forms which had been reacted with pre-immune, unabsorbed immune or absorbed immune rabbit serum. In a control to rule out nonspecific fluorescence, incubation of organisms with antiserum was omitted from the procedure. Slides were made of staphylococci which had been separated from an $\mathrm{I} 8 \mathrm{hr}$ Brain-Heart-Infusion (Difco) culture $\left(37^{\circ}\right)$, washed once and resuspended in saline. Initially, the method used by Karakawa, Rotta \& Krause (1965) in immunofluorescence studies of streptococcal L-forms was applied. However, the most satisfactory preparations of staphylococcal L-forms proved to be smears of growth from broth cultures or of colonies from soft $(0.15 \%)$ agar cultures. Slides were examined under a Reichert u.v. microscope using a BG-I2 exciter filter and an OG-I barrier filter.

\section{RESULTS}

Examination of L-forms for coagulase and clumping factor. The L-form was considered stable when no bacterial colonies developed on penicillin-free medium. The sedimented growth of broth cultures inoculated with L-colonies contained numerous large bodies similar to those described by Marston (196I $b$ ), Weibull (1963) and Williams (I963). Occasionally, in broth cultures, the L-form gave rise to small discrete colonies which, on transfer to fresh broth, produced the usual diffuse growth. Typical L-colonies developed from either the diffuse growth or the discrete colonies.

Coagulase-production by L-forms was demonstrated by the plasma-fibrinogensoft agar method as well as by use of broth cultures in the regular plasma clotting test. Clumping factor activity could not be detected in fibrinogen-soft agar because compact colonies sometimes developed in the fibrinogen-free soft agar base. The viscous nature of the L-form growth, on agar or in broth, made it unsuitable for use in the slide clumping test usually applied to staphylococci.

Table r. Homologous agglutination titres before and after absorbing Staphylococcus aureus antisera with variants and $L$-forms of $S$. aureus

\begin{tabular}{|c|c|c|c|c|c|c|}
\hline & & & Ant & abso & with & \\
\hline $\begin{array}{c}\text { S. aureus } \\
\text { antiserum }\end{array}$ & & & Cocci & & & $\begin{array}{l}\text { L-form of } \\
\text { immunizing }\end{array}$ \\
\hline $\begin{array}{l}\text { (immunizing } \\
\text { strain) }\end{array}$ & $\begin{array}{l}\text { Unabsorbed } \\
\text { antiserum }\end{array}$ & $\mathrm{J} 17 \mathrm{M}^{*}$ & $604 M^{*}$ & sv $\dagger$ & $\mathrm{K} 6 \dagger$ & $\begin{array}{l}\text { S. aureus } \\
\text { strain }\end{array}$ \\
\hline $\mathrm{J} 17$ & $I / 2560$ & $1 / 1280$ & $1 / 2560$ & -7 & $1 / 10$ & $\mathrm{I} / \mathrm{I} 280$ \\
\hline 604 & $1 / 2560$ & $I / 2560$ & $1 / 1280$ & - & $1 / 10$ & I / I 280 \\
\hline 3189 & $1 / 5120$ & $I / 2560$ & $1 / 2560$ & $1 / 10$ & $1 / 20$ & $I / 2560$ \\
\hline 2253 & $1 / 1280$ & I / I 280 & $1 / 1280$ & - & - & $1 / 320$ \\
\hline 2095 & $I / 2560$ & $I / 2560$ & $1 / 2560$ & $1 / 10$ & $1 / 20$ & I / I 280 \\
\hline $\mathrm{s}$ & $\mathrm{I} / \mathrm{I} 280$ & I $/ 640$ & $I / 640$ & - & $1 / 10$ & $\mathrm{I} / 640$ \\
\hline
\end{tabular}

* $\mathrm{J} 17 \mathrm{M}$ and $604 \mathrm{M}$ are coagulase-negative, clumping factor-negative variants of $S$. aureus strains $\mathrm{J}_{17}$ and 604, respectively.

$\uparrow \mathrm{sv}$ and $\mathrm{k} 6$ are encapsulated, coagulase-positive strains which do not clump in fibrinogen.

$\ddagger$ No reaction observed in lowest serum ( $/ / 10)$ dilution tested.

Agglutination and clumping inhibition reactions. Prior to immunization, sera of rabbits were negative for clumping-inhibiting antibody and in no instance was the agglutination titre for strains used higher than I/IO. Titres of immune sera ranged 
from $I / I 280$ to $I / 5 I 20$ for agglutinating antibody and from $I / 320$ to $I / 2560$ for clumping-inhibiting antibody.

There was no significant change in either reaction as a result of absorption with coagulase-negative, clumping factor-negative (J I7M or 604M) cocci, nor did L-form absorption have any appreciable effect, except in the case of strain 2253. In the three instances tested (strains 604, 3189 and 2095) absorption of antiserum with the concentrated supernatant fluid of L-form broth cultures caused no change in titres. The encapsulated, coagulase-positive, clumping factor-negative (SV or K6) cocci removed both agglutinating and clumping-inhibiting antibodies. However, as a result of absorption with these cocci there was a greater decrease in agglutination titres than in clumping inhibition titres.

Tables $\mathrm{I}$ and 2 show the agglutination and clumping inhibition titres, respectively, of antisera after repeated absorptions with variant staphylococci and with L-forms of the immunizing strain.

Table 2. Homologous clumping inhibition titres before and after absorbing Staphylococcus aureus antisera with variants and $L$-forms of $S$. aureus

\begin{tabular}{|c|c|c|c|c|c|c|}
\hline \multirow{3}{*}{$\begin{array}{c}\text { S. aureus } \\
\text { antiserum } \\
\text { (immunizing } \\
\text { strain) }\end{array}$} & \multirow{3}{*}{$\begin{array}{c}\text { Unabsorbed } \\
\text { antiserum }\end{array}$} & \multicolumn{5}{|c|}{ Antiserum absorbed with } \\
\hline & & \multicolumn{4}{|c|}{ Cocci (strain) } & \multirow{2}{*}{$\begin{array}{l}\text { L-form of } \\
\text { immunizing } \\
S . \text { aureus } \\
\text { strain }\end{array}$} \\
\hline & & $\mathrm{J} 17 \mathrm{M}^{*}$ & $604 M^{*}$ & svi & $\mathrm{k} 6 \dagger^{\dagger}$ & \\
\hline J 17 & I $/ 2560$ & I/I 280 & $I / 2560$ & $1 / 160$ & $1 / 320$ & $1 / 1280$ \\
\hline 604 & I $/ 1280$ & $\mathrm{I} / \mathrm{I} 28 \mathrm{O}$ & I $/ \mathbf{I} 280$ & $I / 20$ & $\mathrm{I} / 40$ & I $/ 640$ \\
\hline 3189 & $I / 2560$ & $I / 2560$ & $I / 2560$ & $1 / 160$ & $1 / 640$ & I $/ 1280$ \\
\hline 2253 & $1 / 320$ & $1 / 320$ & $1 / 320$ & $\mathrm{I} / 20$ & $1 / 40$ & $1 / 160$ \\
\hline 2095 & $I / 640$ & $1 / 640$ & $1 / 640$ & $\mathrm{I} / 80$ & $1 / 160$ & $1 / 320$ \\
\hline $\mathrm{s}$ & $1 / 2560$ & $\mathrm{I} / \mathrm{I} 280$ & $I / 2560$ & $1 / 320$ & $1 / 640$ & $\mathrm{I} / \mathrm{I} 280$ \\
\hline
\end{tabular}

Immunodiffusion reactions of L-forms. A zone of precipitate surrounded L-colonies on agar medium containing homologous Staphylococcus aureus antiserum. Absorption of the antiserum with cocci of the coagulase-negative (JI7 M or $640 \mathrm{M}$ ) variants had no observable effect on this reaction. No precipitation developed when the antiserum was absorbed with typical $S$. aureus or with the encapsulated, coagulasepositive, clumping factor-negative (sv or $\mathrm{K} 6$ ) cocci.

Fluorescent-antibody reactions. Results with strain $\mathrm{J}$ 7, as presented in Table 3, are typical of those obtained when other Staphylococcus aureus strains were tested with homologous antisera.

Pre-immune serum caused slight fluorescence of coagulase-positive strains, regardless of their clumping activity, but no fluorescence of the coagulase-negative variants or L-forms was observed. Fluorescence of coagulase-positive staphyloccoci was eliminated by absorption of pre-immune serum with any coagulase-positive strain, but not with coagulase-negative variants or L-forms.

Each unabsorbed antiserum produced bright fluorescence of all coagulase-positive strains and weak fluorescence of the coagulase-negative variants and L-forms. 
Absorption of an antiserum with the homologous staphylococcus eliminated fluorescence of all staphylococci and L-forms tested. Use of coagulase-negative variant cocci as absorbing agents had no effect on the ability of an antiserum to produce fluorescence of typical Staphylococcus aureus, although the reaction of the encapsulated, coagulasepositive, clumping factor-negative (sv and $\mathrm{k} 6$ ) cocci was somewhat weakened. The fluorescent reaction of typical $S$. aureus was diminished and that of coagulase-negative variants and L-forms was eliminated by absorption of antisera with cocci of strains SV or K6. Surprisingly, absorption with SV or $\mathrm{k} 6$ cocci only slightly decreased the effectiveness of $S$. aureus antisera in producing fluorescence of these encapsulated cells.

Table 3. Effect of absorption of Staphylococcus aureus strain 517 antiserum with clumping factor-negative variants and L-forms of $S$. aureus on indirect fluorescent-antibody reactions

Degree of fluorescence

\begin{tabular}{|c|c|c|c|c|c|c|c|c|}
\hline \multirow{3}{*}{$\begin{array}{c}S . \text { aureus } \\
\text { tested } \\
\text { (strain) }\end{array}$} & \multirow{3}{*}{$\begin{array}{l}\text { Pre-immune } \\
\text { serum }\end{array}$} & \multirow{3}{*}{$\begin{array}{l}\text { Unabsorbed } \\
\text { immune } \\
\text { serum }\end{array}$} & \multicolumn{6}{|c|}{ Antiserum absorbed with } \\
\hline & & & \multicolumn{5}{|c|}{ Cocci (strain) } & \multirow{2}{*}{$\begin{array}{l}\text { L-form of } \\
\text { immunizing } \\
\text { strain (J I 7) }\end{array}$} \\
\hline & & & $\mathrm{J} 17$ & $\mathrm{~J} I 7 \mathrm{M}$ & $604 \mathrm{M}$ & sv & к 6 & \\
\hline \multicolumn{9}{|c|}{$\mathrm{C}+/ \mathrm{CF}+*$} \\
\hline J17 & $+\dagger$ & +++ & - & $++t$ & +++ & $+t$ & ++ & $++t$ \\
\hline 604 & + & +++ & - & $+t+$ & +++ & ++ & ++ & +++ \\
\hline 2095 & + & $+t+$ & - & +++ & +++ & ++ & ++ & +++ \\
\hline 2253 & + & +++ & - & $+t+$ & +++ & ++ & ++ & $++t$ \\
\hline $\mathbf{s}$ & + & +++ & - & +++ & +++ & $+t$ & ++ & +++ \\
\hline \multicolumn{9}{|l|}{$\mathrm{C}+/ \mathrm{CF}-$} \\
\hline sv & + & +++ & - & ++ & ++ & $+t$ & ++ & +++ \\
\hline k 6 & + & +++ & - & ++ & ++ & ++ & ++ & +++ \\
\hline \multicolumn{9}{|l|}{$\mathrm{C}-/ \mathrm{CF}-$} \\
\hline J I 7 M & - & + & - & - & - & - & - & + \\
\hline $604 M$ & - & + & - & - & - & - & - & + \\
\hline \multicolumn{9}{|l|}{ L-form } \\
\hline J I 7 & - & + & - & + & + & - & - & - \\
\hline
\end{tabular}

* $\mathrm{C}$, coagulase reaction; $\mathrm{CF}$, clumping factor activity.

$\dagger$ Degrees of fluorescence: +++ , Strong; ++ , moderate; + , weak; - , negligible or none.

\section{DISCUSSION}

Variants of Staphylococcus aureus which are negative for both coagulase and clumping factor apparently possess few, if any, surface antigens characteristic of typical coagulase-positive staphylococci. These staphylococci were not agglutinated by antisera prepared against typical $S$. aureus. Absorption of anti-S. aureus sera with the cocci of coagulase-negative variants caused no significant decrease in $S$. aureus agglutination or clumping inhibition titres. It has been reported that the agglutinating antibody content of sera from rabbits immunized with coagulase-negative variants is remarkably low (Rotter \& Kelly, I966). Loss of protein A (antigen A), as well as of clumping factor antigen, accompanies coagulase-negative variation, as demonstrated by immunodiffusion studies (Blackstock \& Kelly, 1968). Protein A has been recognized as a major agglutinogen of $S$. aureus (Mudd, Yoshida, Li \& Lenhart, 1963).

The encapsulated variants tested (sV and $\mathrm{K} 6$ ) evidently have cell-wall antigens in 
common with those of typical Staphylococcus aureus strains. Following absorption of $S$. aureus antisera with either Sv or $\mathrm{k} 6 \mathrm{cocci}$, homologous agglutination titres were drastically decreased. Partial removal of clumping-inhibiting antibodies by sV and $\mathrm{K} 6$ was an unexpected finding. Although they do not clump in the presence of fibrinogen, these staphylococci apparently have the antigen associated with the clumping reaction. The same conclusion was reached by Blackstock (1968), who found that antisera prepared against such encapsulated staphylococci contained high titres of clumpinginhibiting antibodies. Their failure to clump with fibrinogen could be due to a nonspecific masking effect of the capsule. Another possibility is that a factor essential to cell-fibrinogen interaction may be separate from, though closely associated with, the antigen which functions in the clumping inhibition reaction (Kato \& Omori, 1959). Recently, it was shown that the capsular polysaccharide of the coagulase-positive, clumping factor-negative staphylococci inhibited the fibrinogen precipitating activity of extracts of $S$. aureus (Blackstock et al. I968). However, inhibition of clumping by this polysaccharide was not demonstrated.

L-forms of typical Staphylococcus aureus strains were no more effective in removing agglutinins and clumping-inhibiting antibodies than were coagulase negative, clumping factor-negative variants. A single absorption with the homologous $\mathrm{L}$-form caused no change in titre. A second L-form absorption produced the results shown in Tables I and 2, i.e. a slight decrease in both agglutination and clumping-inhibition titres probably due to dilution of the antisera. Upon centrifugation of broth cultures, Lform growth was deposited in a viscous sediment with sufficient water content to account for the dilution.

Immunodiffusion experiments indicated that the L-forms liberated one or more antigens which were shared with the immunizing Staphylococcus aureus and with the encapsulated variants, but not with the coagulase-negative staphylococci. Free coagulase could be one such antigen. From results of preliminary studies, it appeared that clumping factor was not released into the medium by the L-form. Concentrated supernatant fluid of L-form broth cultures did not interfere with the clumping-inhibiting antibody activity of antisera.

Certain results of the fluorescent-antibody tests are noteworthy. Although preimmune rabbit sera contained antibodies which caused slight fluorescence of coagulase-positive staphylococci, these sera failed to react with the coagulase-negative variants or the L-forms. Immunization with Staphylococcus aureus induced antibodies which gave weak fluorescence with both coagulase-negative variants and L-forms. Identical antigens have been found in extracts of the membranes of the coccal form and the L-form of S. aureus (Pratt, I966). Absorption of antisera with either encapsulated or nonencapsulated, coagulase-positive staphylococci eliminated the fluorescent reaction of $\mathrm{L}$-forms. Coagulase-negative variants were unable to remove the antibody responsible for fluorescence of $L$-forms.

Evidence that the L-form does not possess clumping factor can be found in results of the clumping-inhibition and fluorescent-antibody tests. L-forms did not remove clumping-inhibiting antibodies from Staphylococcus aureus antiserum. By use of the encapsulated staphylococci (sv and $\mathrm{k}$ 6) as absorbing antigens, antisera with agglutinin titres of $I / 10$ or less and clumping inhibition titres in the range of $I / 80$ to $I / 640$ were prepared. Such antisera did not cause fluorescence of the L-forms

Application of the fluorescent-antibody technique to L-forms was most successful 
when growth was taken from broth or soft agar cultures. Entire colonies, easily separated from the soft agar medium, were particularly suitable for these studies.

This investigation was supported by Training Grant no. 5 ToI AIoor62 and by Grant AI0619 from the National Institute of Allergy and Infectious Diseases.

\section{REFERENCES}

Alami, S. Y. \& Kelly, F. C. (1959). Demonstration of staphylococcal clumping factor and free coagulase in soft agar media. Journal of Bacteriology 78, 537.

BLACKSTOCK, R. (1968). Surface components of Staphylococcus aureus and the fibrinogen-cell clumping reaction. M.S. Thesis, University of Oklahoma Medical Center.

Blackstock, R., Hyde, R. M. \& Kelly, F. C. (1968). Inhibition of fibrinogen reaction by polysaccharide of encapsulated Staphyloccocus aureus. Journal of Bacteriology 96, 799.

BLACKSTOCK, R. \& KELLY F. C. (I968). Comparison of staphylococcal clumping factor and protein A. Journal of Bacteriology $96,855$.

Cohen, J. O. \& SMiтh, P. B. (I964). Serological typing of Staphylococcus aureus. Typing by slide agglutination and comparison by phage typing. Journal of Bacteriology 88, 1364.

DUTHIE, E. S. (1954). Evidence of two forms of staphylococcal coagulase. Journal of General Microbiology 10, 427.

Gorrill, R. H., KLYHN, K. M. \& MCNeIL, E. M. (1966). The initiation of infection in the mouse kidney after intravenous injection of bacteria. Journal of Pathology and Bacteriology 91, I57.

Hamburger, M. \& Carleton, J. (1966). Staphylococcal spheroplasts and L colonies. II. Conditions conducive to reversion of spheroplasts to vegetative staphylococci. Journal of Infectious Diseases Ix6, 544.

Hunt, G. A. \& Moses, A. J. (1958). Acute infection of mice with the SMITH strain of Staphylococcus aureus. Science, New York 128, 1574.

Karakawa, W. W., RotTa, J. \& Krause, R. M. (I965). Detection of M protein in colonies of streptococcal L forms by immunofluorescence. Proceedings of the Society for Experimental Biology and Medicine 1r8, 198.

KATo, Y. \& OмORI, G. (I959). Extraction of bound coagulase from staphylococcal cells. Biken's Journal 2, 321.

Marston, J. (I961 a). Observations of L forms of staphylococci. Journal of Infectious Diseases I08, 75 .

Marston, J. (1961 b). Cultivation of staphylococcal L forms in liquid medium. Journal of Bacteriology $81,832$.

Mattman, L. H., Turnstall, L. H. \& Rossmoore, H. W. (1961). Induction and characteristics of staphylococcal L forms. Canadian Journal of Microbiology 7, 705.

Mudd, S., Yoshida, A., LI, I. W. \& LenharT, N. A. (I963). Identification of a somatic antigen of Staphylococcus aureus critical for phagocytosis by human blood leucocytes. Nature, London r99, I200.

PRATT, B. C. (1966). Cell wall deficiencies in L forms of Staphylococcus aureus. Journal of General Microbiology 42, I 5 .

RotTer, J. \& KeLLY, F. C. (1966). Serological reactions associated with clumping factor of Staphylococcus aureus. Journal of Bacteriology 9r, 588.

Weibull, C. (1963). Size of minimal reproductive units of bacterial L-forms. Proceedings of the Society for Experimental Biology and Medicine $113,32$.

Williams, R. E. O. (1963). L forms of Staphylococcus aureus. Journal of General Microbiology 33, 325. 